\title{
Flexural and diametral tensile strength of composite resins
}

\author{
Álvaro Della Bona ${ }^{(a)}$ \\ Paula Benetti $i^{(b)}$ \\ Márcia Borba(c) \\ Dileta Cecchetti ${ }^{(d)}$
}

(a) $\mathrm{PhD}$ in Biomaterials, Senior Professor of Prosthodontics and Occlusion, School of Dentistry, University of Passo Fundo,

Passo Fundo, RS, Brazil.

(b) MSc Student, Operative Dentistry, School of Dentistry, Federal University of Pelotas, Pelotas, RS, Brazil.

(c) PhD Student, Dental Materials, School of Dentistry, University of São Paulo, São Paulo, SP, Brazil.

(d) MSc in Statistics, Professor, Institute of Biological Sciences, University of Passo Fundo, Passo Fundo, RS, Brazil.

\author{
Corresponding author: \\ Álvaro Della Bona \\ Universidade de Passo Fundo \\ Faculdade de Odontologia \\ Campus I, B. São José, BR 285, Km 171 \\ Passo Fundo - RS - Brazil \\ CEP: 99001-970 \\ E-mail: dbona@upf.br
}

\begin{abstract}
This study evaluated the flexural strength $\left(\sigma_{\mathrm{f}}\right)$ and the diametral tensile strength $\left(\sigma_{t}\right)$ of light-cured composite resins, testing the hypothesis that there is a positive relation between these properties. Twenty specimens were fabricated for each material (Filtek Z250-3M-Espe; AMAmelogen, Ultradent; VE- Vit-l-escence, Ultradent; EX- Esthet-X, Dentsply/Caulk), following ISO 4049 and ANSI/ADA 27 specifications and the manufacturers' instructions. For the $\sigma_{t}$ test, cylindrical shaped $(4 \mathrm{~mm}$ x $6 \mathrm{~mm})$ specimens $(\mathrm{n}=10)$ were placed with their long axes perpendicular to the applied compressive load at a crosshead speed of $1.0 \mathrm{~mm} / \mathrm{min}$. The $\sigma_{\mathrm{f}}$ was measured using the 3-point bending test, in which bar shaped specimens $(\mathrm{n}=10)$ were tested at a crosshead speed of $0.5 \mathrm{~mm} / \mathrm{min}$. Both tests were performed in a universal testing machine (EMIC 2000) recording the fracture load $(\mathrm{N})$. Strength values $(\mathrm{MPa})$ were calculated and statistically analyzed by ANOVA and Tukey $(\alpha=0.05)$. The mean and standard deviation values $(\mathrm{MPa})$ were Z250-45.06 \pm 5.7; AM-35.61 \pm 5.4 ; VE-34.45 \pm 7.8 ; and EX-42.87 \pm 6.6 for $\sigma_{\mathrm{t}}$; and Z250-126.52 \pm 3.3 ; AM-87.75 \pm 3.8 ; VE-104.66 \pm 4.4 ; and EX-119.48 \pm 2.1 for $\sigma_{\mathrm{f}}$. EX and Z250 showed higher $\sigma_{\mathrm{t}}$ and $\sigma_{\mathrm{f}}$ values than the other materials evaluated $(\mathrm{p} \leq 0.05)$, which followed a decreasing trend of mean values. The results confirmed the study hypothesis, showing a positive relation between the material properties examined.
\end{abstract}

Descriptors: Composite resins; Tensile strength; Physical properties. 


\section{Introduction}

The increased demand for esthetic restorations and need of improvement of the mechanical properties of composite resins contributed for the development of these materials, which have been improved to adequately meet the clinical requirements of direct and indirect restorations in anterior and posterior teeth. ${ }^{1-3}$

Clinical application of composite resins for restoration of posterior teeth requires some mechanical properties to avoid marginal degradation and fracture of restorations. Investigations of new materials to meet this need led to the development of highviscosity resins. These resins have advantages of achieving proximal contact points, reducing polymerization shrinkage and resisting to higher stresses for posterior teeth restoration. ${ }^{4}$

Composite resin posterior restorations are influenced by mechanical properties, such as fracture toughness, compressive strength, flexural strength, wear resistance and diametral tensile strength. ${ }^{1,5}$

The variation in strength between different composites may be explained by the differences in the chemical composition of the matrix, fillers, and filler size and distribution. ${ }^{4,6}$ Thus, a reduction in size and increase in volume of fillers are directly proportional to an increase in compressive strength and surface hardness. ${ }^{7,8}$

A higher amount of fillers in composite resins reduces the shrinkage but also increases the elastic modulus, which reduces the flowing ability, thus not compensating for the polymerization shrinkage, ultimately leading to higher intrinsic stress, adhesive failure and reduced bond strength between material and tooth structure. ${ }^{9}$

Composite resins have better mechanical properties, such as compressive strength, than other restorative composites such as conventional or resinmodified glass ionomers, suggesting a longer clinical life in regions submitted to occlusal loads. ${ }^{10}$

The literature reports a positive correlation between compressive strength and diametral tensile strength. In both types of testing, specimens are submitted to a compressive load applied at different planes, and fracture occurs as a result of tensile and complex shear stresses within the material. ${ }^{9}$
Diametral tensile strength testing was developed to investigate brittle materials with little or no plastic deformation. In this test, a cylindrical specimen is submitted to a compressive load in the diametral plane, which is perpendicular to the longitudinal axis. ${ }^{9,11}$

There is a close relationship between fatigue resistance, hardness, elastic modulus, compressive strength and diametral tensile strength of materials. A restorative material with high compressive strength, flexural strength and diametral tensile strength may be clinically applied and should be resistant to masticatory forces. ${ }^{2,3,11}$

The flexural strength test employs rectangular bar specimens submitted to three- or four-point bending, producing tensile stresses on the lower surface of the specimen and compressive stresses on the upper surface, where load is applied., ${ }^{9,11}$ These methods have been recommended to test the strength of composites. $^{12,13}$

Therefore, the aim of this study was to evaluate the flexural strength and diametral tensile strength of light-cured composite resins, testing the hypothesis that there is a positive relationship between these properties.

\section{Material and Methods}

This study investigated the flexural strength and diametral tensile strength properties of four lightcured composite resins (Table 1). The specimens were fabricated according to the manufacturers' instructions, ISO $4049^{13}$ and ANSI/ADA specification n. $27 .^{12}$

For the diametral tensile test, 10 cylindrical specimens were fabricated from each material $(4.0 \pm 0.1 \mathrm{~mm}$ in diameter $\times 6.0 \pm 0.1 \mathrm{~mm}$ in height $)$ according to specification n. 27 of ANSI/ADA, in 1993..$^{12}$ The composite was inserted and packed in a cylindrical glass mold whose ends were blocked with two glass slabs. The material was light-cured (XL1500, 3M Dental Products, light intensity $>450 \mathrm{~mW} / \mathrm{cm}^{2}$ ) for $20 \mathrm{~s}$ through each end of the cylinder. The specimens were removed from the mold and excess material was removed using a 600 grit $\mathrm{SiC}$ paper. The dimensions of specimens were checked using a digital caliper (Digimatic caliper, 
Table 1 - Composite resins investigated in the present study.

\begin{tabular}{l|l|l|l|l}
\hline Composite resin & \multicolumn{1}{|c|}{ Brand (manufacturer) } & Shade, batch & \multicolumn{1}{|c}{ Composition of organic matrix* } & \multicolumn{1}{|c}{ Composition of filler particles* $^{*}$} \\
\hline Z250 & $\begin{array}{l}\text { Filtek Z250 (3M-Espe, St. } \\
\text { Paul, MN, USA) }\end{array}$ & A3, 2LR & UEDMA, Bis-EMA and Bis-GMA & Zirconia and silica particles \\
\hline AM & $\begin{array}{l}\text { Amelogen (Ultradent Inc., } \\
\text { South Jordan, UT, USA) }\end{array}$ & A2, 3B6P & Bis-GMA & $\begin{array}{l}52 \text { vol\% of silica dioxide and silicates } \\
\text { particles }\end{array}$ \\
\hline VE & $\begin{array}{l}\text { Vit-l-escence (Ultradent Inc., } \\
\text { South Jordan, UT, USA) }\end{array}$ & A2, 39MC & Bis-GMA & 58 vol\% of silica particles \\
\hline EX & $\begin{array}{l}\text { Esthet-X (Dentsply Ind. e Com. } \\
\text { Ltda., Petrópolis, RJ, Brazil) }\end{array}$ & A2, 010521 & $\begin{array}{l}\text { Bis-GMA, Bis-EMA and } \\
\text { TEGDMA }\end{array}$ & $\begin{array}{l}\text { Silanized fluoride, aluminum and } \\
\text { barium borosilicate glass, colloidal } \\
\text { silica and nanometric silica. }\end{array}$ \\
\hline
\end{tabular}

*The composition of organic matrix and fillers was provided by the manufacturers.

Mitutoyo Corp., Tokyo, Japan). The specimens were then stored in distilled water at $37^{\circ} \mathrm{C}$ for $24 \mathrm{~h}$.

The specimens were tested under compressive load in a universal testing machine (EMIC 2000, Equipamentos e Sistemas de Ensaio LTDA., São José dos Pinhais, PR, Brazil). Load was applied vertically on the lateral portion of the cylinder, at a crosshead speed of $1.0 \mathrm{~mm} / \mathrm{min}$, producing tensile stresses perpendicular to the vertical plane passing through the center of the specimen. ${ }^{9}$

After each compressive test, the fracture load (F), in Newtons (N), was recorded and the diametral tensile strength $\left(\sigma_{t}\right)$ (in $\mathrm{MPa}$ ) was calculated as follows:

$$
\sigma_{\mathrm{t}}=2 \mathrm{~F} / \pi \mathrm{dh}
$$

where:

$$
\begin{aligned}
& \mathrm{d} \text { : diameter }(4 \mathrm{~mm}) ; \\
& \mathrm{h}: \text { height }(6 \mathrm{~mm}) \text { of specimens; } \\
& \pi: 3.1416 .
\end{aligned}
$$

For the three-point flexural strength test, 10 bar-shaped specimens were fabricated from each composite resin, following the manufacturers' instructions and ISO4049. ${ }^{13}$ The composite resin was packed inside a stainless steel mold positioned on a glass slab. A thin glass slab was positioned on the mold containing the material, which was lightcured (XL1500, 3M Dental Products, light intensity $>450 \mathrm{~mW} / \mathrm{cm}^{2}$ ) for $20 \mathrm{~s}$ at each third of the upper and lower surfaces of the specimen $(25 \pm 2 \mathrm{~mm}$ x $2 \pm 0.1 \mathrm{~mm}$ x $2 \pm 0.1 \mathrm{~mm})$. All specimens were removed from the mold and polished using a 600 grit $\mathrm{SiC}$ paper to remove excess material. The dimensions of specimens were checked using a digital caliper (Digimatic caliper, Mitutoyo Corp., Tokyo, Japan). The specimens were then stored in distilled water at $37^{\circ} \mathrm{C}$ for $24 \mathrm{~h}$.

Specimens were submitted to the three-point bending test in a universal testing machine (EMIC 2000, Equipamentos e Sistemas de Ensaio LTDA., São José dos Pinhais, PR, Brazil) at a crosshead speed of $0.5 \mathrm{~mm} / \mathrm{min}$ until fracture. ${ }^{14}$

The maximum fracture load $(\mathrm{F}$, in $\mathrm{N})$ of each specimen was recorded, and the flexural strength $\left(\sigma_{\mathrm{f}}\right)$, in MPa, was calculated as follows:

$$
\sigma_{\mathrm{f}}=3 \mathrm{Fl} / 2 \mathrm{bh}^{2}
$$

where:

\section{1: distance between the supporting} rollers $(20 \mathrm{~mm})$;

b: specimen width ( 2 $\mathrm{mm})$;

h: specimen height $(\sim 2 \mathrm{~mm})$.

Results were statistically analyzed using analysis of variance (ANOVA) and Tukey test, at a significance level of $5 \%$.

\section{Results}

The mean and standard deviation values (MPa) for the diametral tensile strength $\left(\sigma_{t}\right)$ and the flexural strength $\left(\sigma_{\mathrm{f}}\right)$ are summarized in Table 2.

The mean $\sigma_{t}$ values for Z250 and EX were significantly higher than those of the other materials investigated $(\mathrm{p}<0.05)$, indicating that these restorative materials support higher compressive load than 
Table 2 - Mean and standard deviation values of diametral tensile strength and flexural strength, and statistical grouping.

\begin{tabular}{l|c|c}
\hline Groups & $\begin{array}{c}\text { Diametral tensile } \\
\text { strength }(\mathrm{MPa})\end{array}$ & $\begin{array}{c}\text { Flexural } \\
\text { strength }(\mathrm{MPa})\end{array}$ \\
\hline Z250 & $45.06 \pm 5.7 \mathrm{~A}$ & $126.52 \pm 3.3 \mathrm{a}$ \\
\hline $\mathrm{EX}$ & $42.87 \pm 6.6 \mathrm{~A}$ & $119.48 \pm 2.1 \mathrm{a}$ \\
\hline $\mathrm{VE}$ & $34.45 \pm 7.8 \mathrm{~B}$ & $104.66 \pm 4.4 \mathrm{~b}$ \\
\hline $\mathrm{AM}$ & $35.61 \pm 5.4 \mathrm{~B}$ & $87.75 \pm 3.8 \mathrm{c}$ \\
\hline
\end{tabular}

Mean values followed by similar letters in the column do not show statistical difference $(p \geq 0.05)$.

the other materials. There was no significant difference between the mean $\sigma_{t}$ values for composites VE and AM.

Since brittle materials are less resistant under tension and there is development of tensile stresses perpendicular to the long axis of specimens, ${ }^{11}$ these stresses probably accounted for the fracture, which always occurred along the vertical plane of load application and followed the long axis of specimens.

The materials Z250 and EX presented statistically higher mean $\sigma_{f}$ values than the other materials investigated $(\mathrm{p}<0.05)$. Composites Vit-l-escence (VE) and Amelogen (AM) exhibited significantly different values, with lower mean $\sigma_{\mathrm{f}}$ values for the AM composite resin. All fractures initiated at the tensile surface, close to the central region of specimens, thus validating the experiment.

\section{Discussion}

The continuous improvement of mechanical properties of adhesive systems and composite resins still has not eliminated some limitations for the use of these esthetic restorative materials, especially in posterior teeth. However, the limitations are usually related to polymerization shrinkage, reduced wear resistance and fracture resistance, which may be minimized by the scientific understanding of characteristics and properties of these materials with consequent improvement in manufacturing technology. This rationale is supported by the results of some studies, which reported that better mechanical properties values increase the resistance to wear and to fracture, minimizing clinical problems involving anatomic form and marginal adaptation of composite resin restorations. . $^{5,11,15}$

The material selection for this study was based on clinical use, manufacturer's recommendations and literature support.

The results of this study showed that the microhybrid composite resins Amelogen (AM) and Vitl-escence (VE) presented the lowest mean $\sigma_{t}$ and $\sigma_{f}$ values (Table 2). In the flexural strength test, the VE composite resin exhibited significantly higher mean values than the AM, which may be explained by the filler volume difference between these two materials (Table 1). In the diametral tensile test, however, there was no statistical difference between VE and AM composite resins.

Esthet-X is a microhybrid composite resin indicated for anterior and posterior restorations, with mean particle size smaller than $1 \mu \mathrm{m}$, in addition to the colloidal silica measuring $0.04 \mu \mathrm{m}$ and nanometric silica particles. This microstructure along with the composition described in Table 1 are, probably, the main reasons for the high mean $\sigma_{f}$ and $\sigma_{t}$ values showed by this composite (Table 2). Similar mean $\sigma_{f}$ values were previously reported. ${ }^{16}$

The diametral tensile strength test may reveal different values for apparently similar materials. However, this variation has been explained by the difference between the polymeric matrix, size of fillers and bond between fillers and matrix. ${ }^{17}$ The matrix of most resins is composed of bisphenol-A glycidyl-methacrylate (Bis-GMA), which is an aromatic ester of a dimethacrylate, synthesized from an epoxy resin and methyl methacrylate; thus, it is rigid yet presents high viscosity. The viscosity of the polymeric matrix is reduced by the addition of other low molecular weight polymers such as urethane dimethacrylate (UEDMA) or triethyleneglycol dimethacrylate (TEGDMA), as in the composite Filtek Z-250, to improve the incorporation of fillers and increase the degree of conversion of composite resins. Therefore, it has been reported that replacing BisGMA by TEGDMA increases the diametral tensile strength yet reduces the flexural strength, whereas replacing either Bis-GMA or TEGDMA by UEDMA increases the diametral strength and flexural strength, ${ }^{17}$ which was confirmed by the results 
in the present study. Similar mean $\sigma_{\mathrm{t}}$ values were reported by other studies. ${ }^{18,19}$

Weinmann et al. ${ }^{15}$ (2005) observed a higher mean $\sigma_{\mathrm{f}}$ value for composite Filtek Z250 (166 MPa) than that observed in the present study $(126 \mathrm{MPa})$, which in turn were higher than the mean $\sigma_{f}$ value reported by Palin et al. ${ }^{11}$ (2003) (92 MPa). The matrix of this composite resin contains UEDMA and modified urethane (Bis-EMA), in addition to Bis-GMA, which reduces the polymerization shrinkage and the intrinsic stresses of the material. Moreover, this microhybrid composite has $60 \%$ of small silica particles, increasing the incorporation of a higher volume of fillers in the polymeric matrix that allows for better accommodation of particles during polymerization and provides good surface smoothness after polishing. The high mean $\sigma_{\mathrm{f}}$ and $\sigma_{\mathrm{t}}$ values of $\mathrm{Z} 250$ may be explained by its higher volume of inorganic fillers, which improves its intrinsic properties. Recently, Palin et al. ${ }^{20}$ (2005) performed a similar study using Z250 and reported a mean $\sigma_{\mathrm{f}}$ value of $127 \mathrm{MPa}$, which agrees with the mean $\sigma_{f}$ value found in this study $(126.5 \mathrm{MPa})$. As the Z250 is indicated for direct and indirect restorations of anterior and posterior teeth, the ISO 4049 standard ${ }^{13}$ recommends a mini-

\section{References}

1. Atai M, Nekoomanesh M, Hashemi SA, Amani S. Physical and mechanical properties of an experimental dental composite based on a new monomer. Dent Mater. 2004;20(7):663-8.

2. Cohen BI, Volovich Y, Musikant BL, Deutsch AS. Comparison of the flexural strength of six reinforced restorative materials. Gen Dent. 2001;49(5):484-8.

3. Levartovsky S, Kuyinu E, Georgescu M, Goldstein GR. A comparison of the diametral tensile strength, the flexural strength, and the compressive strength of two new core materials to a silver alloy-reinforced glass ionomer material. J Prosthet Dent. 1994;72(5):481-5.

4. Bonilla ED, Mardirossian G, Caputo AA. Fracture toughness of posterior resin composites. Quintessence Int. 2001; 32(3):206-10.

5. Manhart J, Chen H, Hamm G, Hickel R. Buonocore Memorial Lecture. Review of the clinical survival of direct and indirect restorations in posterior teeth of the permanent dentition. Oper Dent. 2004;29(5):481-508. mum $\sigma_{\mathrm{f}}$ value of $100 \mathrm{MPa}$, which was confirmed in the present study. Yet, the minimum three-point flexural strength value for light-cured direct restorative materials is $80 \mathrm{MPa} \cdot{ }^{13}$ In this study, the lower mean flexural strength value was observed for AM (87.7 MPa). Thus, all materials investigated showed higher mean $\sigma_{f}$ values than the ones recommended by the ISO, ${ }^{13}$ suggesting that these materials can be used as direct restorative materials.

The quality of restorative materials, indicated by their physical properties, is important for material selection and clinical indication. High compressive, flexural and diametral tensile strength values are important for restorative materials support the occlusal forces of posterior teeth. ${ }^{9}$ This rationale and the results of this study indicate that the composite resins Z250 and EX will support compressive mastication forces more effectively than the other materials investigated.

\section{Conclusion}

The results of the present study revealed a positive relationship between the mean flexural strength and mean diametral tensile strength values for the composite resins investigated, confirming the study hypothesis.

6. Adabo GL, Santos Cruz CA, Fonseca RG, Vaz LG. The volumetric fraction of inorganic particles and the flexural strength of composites for posterior teeth. J Dent. 2003;31(5):353-9.

7. Sabbagh J, Ryelandt L, Bachérius L, Biebuyck JJ, Vreven J, Lambrechts $\mathrm{P}$ et al. Characterization of the inorganic fraction of resin composites. J Oral Rehabil. 2004;31(11):1090-101.

8. Willems G, Lambrechts P, Braem M, Celis JP, Vanherle G. A classification of dental composites according to their morphological and mechanical characteristics. Dent Mater. 1992;8(5):310-9.

9. Anusavice KJ. Phillips: science of dental materials. $11^{\text {th }}$ ed. St. Louis: W B Saunders; 2003.

10. Xu X, Burgess JO. Compressive strength, fluoride release and recharge of fluoride-releasing materials. Biomater. 2003;24(14):2451-61.

11. Palin WM, Fleming GJ, Burke JF, Marquis PM, Randall RC. The reliability in flexural strength testing of a novel dental composite. J Dent. 2003;31(8):549-57. 
12. American National Standard. American Dental Association Specification n. 27 for Resin-based filling materials; 1993.

13. International Organization for Standardization: ISO 4049 Dentistry - Polymer-based filling, restorative and luting materials. $3^{\text {rd }}$ ed; 2000.

14. Della Bona A, Anusavice KJ, DeHoff PH. Weibull analysis and flexural strength of hot-pressed core and veneered ceramic structures. Dent Mater. 2003;19(7):662-9.

15. Weinmann W, Thalacker C, Guggenberger R. Siloranes in dental composites. Dent Mater. 2005;21(1):68-74.

16. Ferracane JL, Ferracane LL, Musanje L. Effect of light activation method on flexural properties of dental composites. Am J Dent. 2003;16(5):318-22.
17. Asmussen E, Peutzfeldt A. Influence of UEDMA, BisGMA and TEGDMA on selected mechanical properties of experimental resin composites. Dent Mater. 1998;14(1):51-6.

18. Aguiar FH, Braceiro AT, Ambrosano GM, Lovadino JR. Hardness and diametral tensile strength of a hybrid composite resin polymerized with different modes and immersed in ethanol or distilled water media. Dent Mater. 2005;21(12):1098-103.

19. Geirsson J, Bayne SC, Swift EJ Jr, Thompson JY. Mechanical property characterization of a novel directly-placed ceramic restorative material. Am J Dent. 2004;17(6):417-21.

20. Palin WM, Fleming GJ, Marquis PM. The reliability of standardized flexure strength testing procedures for a light-activated resin-based composite. Dent Mater. 2005; 21(10):911-9. 